\title{
Preparation of Zinc Oxide Nano-Layer on Cotton Fabric for UV Protection Application
}

\author{
Hoda Sharouf $^{1 *}$, Ghazal Tuhmaz ${ }^{2}$, Ziad Saffour ${ }^{2}$
}

\section{Authors affiliations: \\ $\left.1^{*}\right)$ Textile Engineering Dep., Faculty of Petroleum and Chemical Engineering, Albaath University, Syria eng.hoda89@hotmail.com}

2) Textile Engineering Dep., Faculty of Petroleum and Chemical Engineering, Albaath University, Syria

\section{Paper History:}

Received: $25^{\text {th }}$ Nov. 2018

Revised: $4^{\text {th }}$ Jan. 2019

Accepted: 30th Jan. 2019

\begin{abstract}
Zinc oxide nano particles is one of the best choices for ultraviolet protection due to its special properties. In this research, the UV-protection ability of sol gel-derived thin $\mathrm{ZnO}$ films on cotton fabrics was investigated. Various polymers have been used as adhesives to bind the nano-oxide with the surface of the treated fabric. Scanning electron microscopy and UV spectroscopy were carried out to study the properties of the treated fabrics. The results showed that the diameters of the synthesis zinc oxide particles - (68.81, 41.76 and $44.6 \mathrm{~nm}$ ) with (PVA, PVP and CMC) respectively- were of the nanostructure, and the smallest diameter of the particles was produced with polyvinylpyrrolidone as adhesive. Using a spectrophotometer showed a decrease in the transmittance of the studied samples compared with the raw untreated sample of about $23 \%$.
\end{abstract}

Keywords: $\mathrm{ZnO}$, sol gel, UV protection.

$$
\begin{aligned}
& \text { تحضير طبقة نانوية من أوكسيد الزنك على القحاش القطني لتطبيقات الماية من } \\
& \text { الأشعة فوق البنفسجية } \\
& \text { هدى شروف1، غزل طهاز } \\
& \text { إنلاصة: }
\end{aligned}
$$

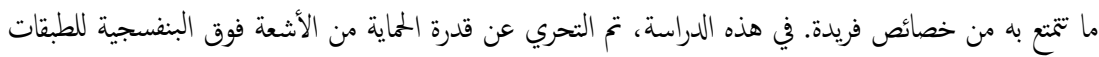

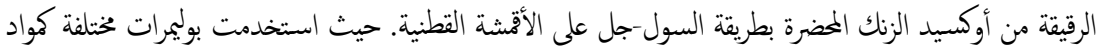

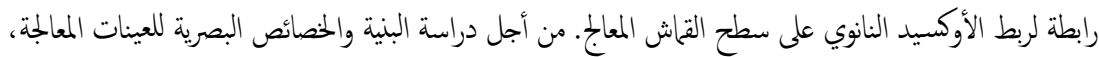



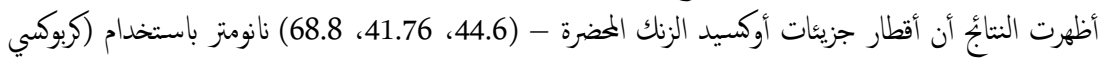

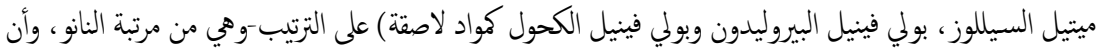

$$
\begin{aligned}
& \text { أصغر أقطار للجزيئات نتجت عند استخدام بولي فينيل البيروليدون كرابط. كما أظهر الاختبار باستخدام بحاز }
\end{aligned}
$$



$$
\begin{aligned}
& \text { كلمات مفتاحية: سول-جل، أوكسيد الزنك النانوي، الحماية من الأشعة فوق البنفسجية. }
\end{aligned}
$$

\section{1-Introduction:}

Since the occurrence of the hole in the ozone layer and because of continued decrease in the thickness of the ozone layer, the ultraviolet severity of solar radiation has increased. The ultraviolet radiation (UVR) is composed of three types: UV-A (315400nm), UV-B (290-315nm), and UV-C (100-290nm). They cause serious health problems such as skin cancer, sunburn and photo aging. Therefore, special attention has been focused recently on the UV transmission of textile. [11]

The fabric UV protective capacity varies significantly depending on many elements such as fiber type, additives, fabric structure, color, pigments and finishing products (different UV absorbers), laundering and washing conditions, wetness, etc. [8]

The absorption spectra of a semiconductor, such as zinc oxide, show strong absorption in the UV region of the light spectrum but only very slight or no absorption of visible light.[10] Zinc oxide seems to be ideal for the preparation of highly UV-absorbing, nanosol-based coatings. Besides, textile materials have intrinsic properties that make them extremely valuable - they are flexible, lightweight, strong, soft, etc. As a result, they are excellent objects for imparting additional functionalities. [13] 
At present, the nanotechnology worldwide-used in the fabric UV-proof finishing can be mainly divided into three different ways, including implanting, spinning, printing and dyeing. [13]

Synthesis of metal nanoparticles with specific properties is a newly established research area that attracts a great deal of attention. Besides, nanostructured metal oxide has been found to display appealing functional, biocompatible, non- toxic, ultraviolet filtering, and anti-bacterial properties. [13]

One of the new and different ways of surface modification methods of textile materials is the sol-gel method, which offers far-reaching possibilities for creating new surface properties.

Nanosols prepared in this way are deposited on fibers/fabrics and dried at an elevated temperature to condense them into cross-linked lyogels. During further drying, the liquid phase is removed and a porous layer (xerogel) is formed on the fiber surface. [12]

The sol-gel method has become an important tool for producing nanoparticles for these reasons: It is a low temperature using process, simple, economic and effective method to produce high quality coatings. Lack of scientific understanding of this complex reaction is one of the major drawbacks of this technique. [4]

Using Sol-gel method offers the ability for modification of many textile materials, obtaining certain properties and to combine different properties in a single coating step. $\mathrm{SiO}_{2}$ nanostructure is synthesized by the Sol-Gel method and thin films are prepared using dip coating technique. [1] Influence of nano titanium dioxide finish, prepared by sol-gel technique, on the ultraviolet protection, antimicrobial, and self-cleaning characteristics of cotton fabrics. [9] The UV-protection ability of sol gel-derived thin $\mathrm{ZnO}$ films on glass substrates was investigated. The obtained results showed excellent UV protection. [5]

$\mathrm{ZnO}$ could be one of the most important nanomaterial in future research and applications. In addition, other major uses of $\mathrm{ZnO}$, especially in the form of powder, pigments, photo catalysts, and ultraviolet absorption. The excellent UV absorption of $\mathrm{ZnO}$ can also be used in cosmetics, paints and plastics. [11] [12]

The present paper describes the deposition of nano-zinc oxide thin-coatings by the sol-gel method on cotton textile substrates to obtain an UV-resistant cotton fabric.

\section{2-Experimental: \\ 2-1-Materials:}

Raw woven plain weave $100 \%$ cotton fabric with the weight of $132 \mathrm{~g} / \mathrm{m}^{2}$ was purchased from the local market. Zinc Acetate $\left(\left(\mathrm{CH}_{3} \mathrm{COO}\right)_{2} \mathrm{Zn} \cdot 2 \mathrm{H}_{2} \mathrm{O}\right.$, Schariau $99 \%$ was used as a precursor. Sodium hydroxide $(\mathrm{NaOH}$, POCh 98\%) was used as a reducing agent. Ethanol $\left(\mathrm{C}_{2} \mathrm{H}_{5} \mathrm{OH}\right.$, Chem-lab 99.8\%) and distilled water were used as solvents. Polyvinyl alcohol (PVA, Lobachemie), Polyvinylpyrrolidone (PVP, Aldrich) and Carboxymethylcellulose (CMC, Titan Media 99\%) were used as adhesives.

\section{2-2-Procedure:}

\section{2-2-1-pretreatment of cotton fabrics:}

Bleaching and desizing were carried out in one bath using sodium hydroxide $(\mathrm{NaOH} 3 \%)$ and hydrogen peroxide $\left(\mathrm{H}_{2} \mathrm{O}_{2} \quad 10 \%\right)$. The treatment proceeded at $100^{\circ} \mathrm{C}$ for one hour. After that, the samples were rinsed with water then leaved to dry at room temperature.

2-2-2-Preparation of the nano zinc oxide solution by sol-gel technique:

Zinc Oxide nanoparticles was synthesized by using sol-gel technique. In order to produce a sol, sodium hydroxide solution was poured to the solution containing zinc acetate. Then, ethanol was added drop wise to the previous solution. After the reaction, white precipitate was formed. [4]

\section{2-2-3-Treatment of cotton fabric:}

Three samples are immersed in the prepared solution taking into account the following:

The first sample: $(1.25 \mathrm{~g})$ of PVA is added to the former solution and mixed until the solution is homogenized. Then, the cotton sample is immersed for $10 \mathrm{~min}$ and dried at $80^{\circ} \mathrm{C}$ for $10 \mathrm{~min}$ after that it was cured at $100^{\circ} \mathrm{C}$ for $5 \mathrm{~min}$. The second sample: PVP is used as an adhesive instead of PVA. The Third sample: CMC is used. [3]

\section{3- Results and Discussion:}

After preparation of the treatment solution and applying it onto the cotton samples then drying and curing processes were applied, the cotton samples were tested using both the scanning electron microscope and the spectrophotometer.

\section{3-1-Scanning Electron Microscope (SEM):}

The nanoparticles obtained were identified by the Scanning Electron Microscope (SEM, VEGA II $\mathrm{XMU}, \mathrm{Czech}$ ) and analyzed using (Imagej) program to get the average nano-particles diameter for each sample.

The mean diameter of the nanoparticles placed on each sample was measured and calculated as shown in Table (1).

Table (1): Average diameter of nano- $\mathrm{ZnO}$ particles in treated samples

\begin{tabular}{|c|c|}
\hline Simple & $\begin{array}{c}\text { Average nano-structure } \\
\text { diameter }(\mathrm{nm})\end{array}$ \\
\hline Nano-ZnO+PVA & 68.81 \\
\hline Nano-ZnO+PVP & 41.76 \\
\hline Nano-ZnO+CMC & 44.6 \\
\hline
\end{tabular}

The above table shows that the diameters of the zinc oxide particles in all the studied samples are of the nano range, which confirms the success of sol-gel technology for obtaining nanomaterial. By observing the diameters of the particles diameters, the smallest value was found when polyvinylpyrrolidone polymer was used as an adhesive and then samples were prepared with Carboxymethylcellulose. This is clear through the images as shown in figures $(1,2$, and 3$)$. 


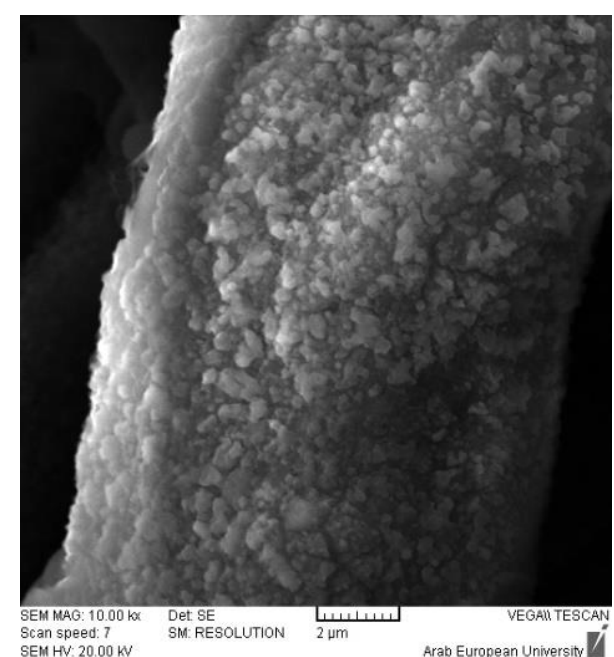

Figure (1): SEM photos of cotton sample treated with nano- $\mathrm{ZnO}+\mathrm{PVA}$

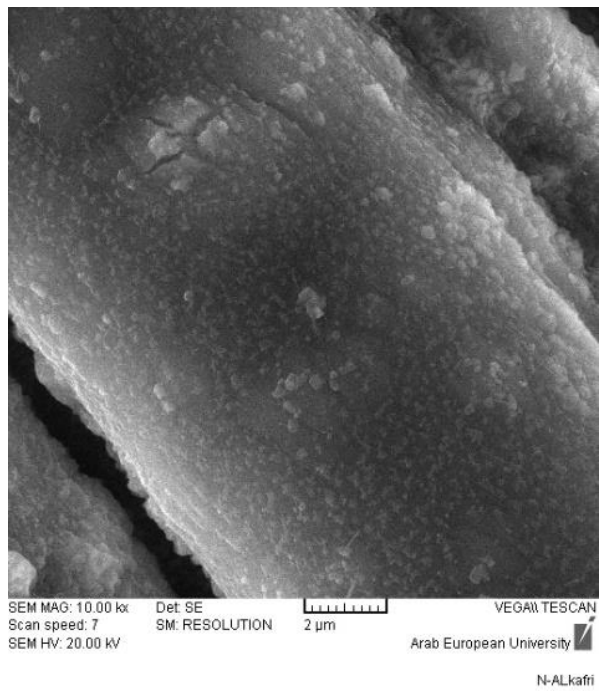

Figure (2): SEM photos of cotton sample treated with nano- $\mathrm{ZnO}+\mathrm{PVP}$

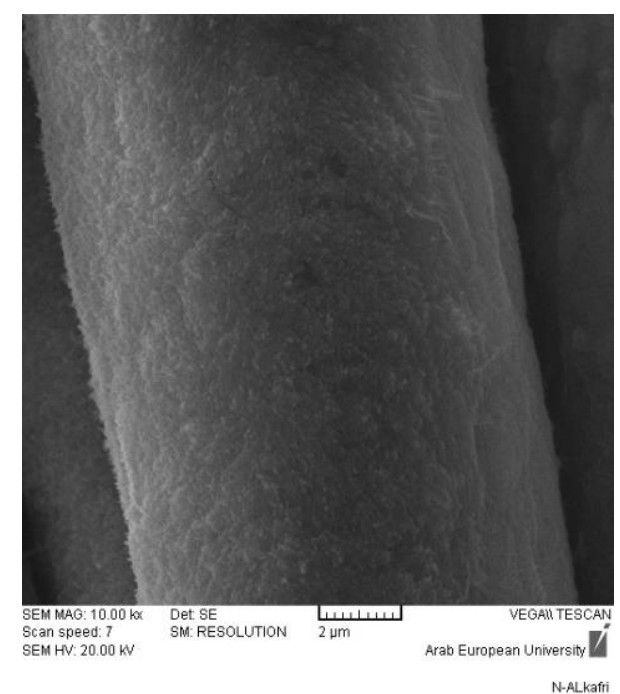

Figure (3): SEM photos of cotton sample treated with nano- $\mathrm{ZnO}+\mathrm{CMC}$

It is known that when the particles are smaller, the active surface is larger and that is lead to more effective. Therefore, the smaller particles give more protection than others do.

\section{3-2- spectrophotometer:}

The transmittance of the treated samples were tested using (JASCO 530 spectrophotometer) within the band (200-400) $\mathrm{nm}$ and the device connected to a computer to record the results.

Figure 4 shows the relationship between ultraviolet transmittance and wavelength of light. There is an improvement in the resistance of UV radiation of the treated fabrics compared with the raw untreated sample, especially the sample treated with nano zinc oxide with polyvinylpyrrolidone, where the transmittance decreased significantly compared to raw fabric. This result is accepted with the research said that, the adding of PVP could increase the UV blocking ability of the treated fabric.[13] It is important to mention that the results of all studied samples were similar to each other, since zinc oxide is the active material that absorbs light in the band of light studied. It is also evident from the figure that there was decreasing in the transmittance of the treated fabric in the band (200-220 nm), i.e. in the band of the most dangerous health package (UVC), where the decrease of the transmittance of about $23 \%$.

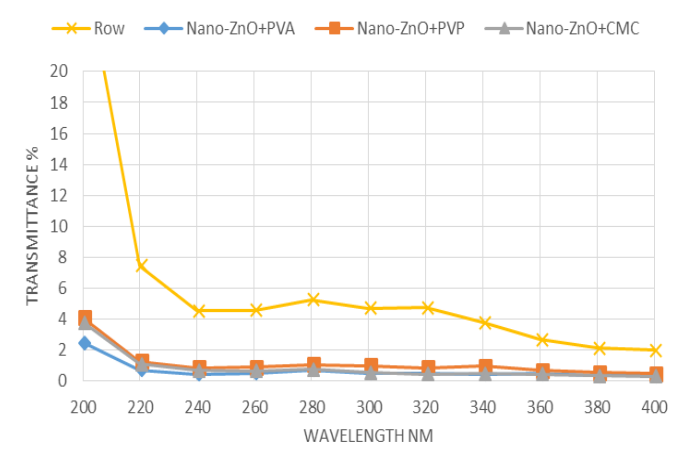

Figure (4): The relationship between ultraviolet Transmittance and wavelength of light.

\section{4-Conclusion:}

The zinc oxide was synthesis by sol-gel technology and applied to cotton fabric using polymer materials (PVA, PVP \& CMC) to bind the zinc oxide with the surface of the cotton fabric. The solution was then applied to the samples and the drying and curing processes were carried out. The scanning electron microscopy images showed that nanoparticles were placed on the surface of the treated fabrics, but the average diameters of these particles differed according to the polymers used as adhesives. PVP was used to obtain the smallest diameters. The spectral survey showed a decrease in the transmittance of UV treated samples compared with the raw sample. The convergence of all samples has been demonstrated in their ability to repel ultraviolet radiation, as the active substance is nano-zinc oxide. 


\section{5- References:}

[1] Abdulmalek N, Dhahir M. Laser Densification of Prepared $\mathrm{SiO}_{2}$ Sol-Gel Thin Films. Baghdad Science Journal Vol 15(2)2018.

[2] Ghamsari M, Alamdari S, Han W, Ho Park H. Impact of nanostructured thin $\mathrm{ZnO}$ film in ultraviolet protection. International Journal of Nanomedicine: 207-216, 2016.

[3] Gouda M, Aljaafari A I. Augmentation of Multifunctional Properties of Cellulosic Cotton Fabric Using Titanium Dioxide Nanoparticles. Advances in Nanoparticles: 29-36, 2012.

[4] Hasuidawani et al. Synthesis of $\mathrm{ZnO}$ Nanostructures Using Sol-Gel Method. Procedia chemistry, Vol 19: 211-216, 2016.

[5] Hussein et al. Preparation $\mathrm{ZnO}$ Thin Film by using Sol-gel-processed and determination of thickness and study optical properties. Journal of Materials and Environmental Science, Vol 4: 423-426, 2011.

[6] Kathirvelu S et al. UV-protection finishing of textile using $\mathrm{ZnO}$ nanoparticles. Indian Journal of Fibre and Textile Research, Vol 34: 367-273, 2009.

[7] Kumar A, Yadav N, Bhatt M, Mishra N, Chaudhary P, Singh R. Sol-Gel Derived Nanomaterial and It's Applications: A Review. Research Journal of Chemical Sciences, Vol 5: 98-105, 2015.

[8] Paul R (Ed). Functional Finishes for Textiles: 469-471. Elsevier, 2015.

[9] Sundaresan K, Sivakumar A, Vigneswaran C, Ramachandran T. Influence of nano titanium dioxide finish, prepared by sol-gel technique, on the ultraviolet protection, antimicrobial, and self-cleaning characteristics of cotton fabrics. Journal of Industrial Textiles 0(00). 2011.

[10] Textor T. Surface Modification of Textile: chapter 9. Elsevier, 2009

[11] Vihodceva S, Kuklet S. Cotton Textile Surface Investigation Before and After Deposition of the $\mathrm{ZnO}$ Coating by Sol-gel Method. Journal of Nano and Electronic Physics, Vol 5, 2013.

[12] Vihodceva S, Kukle S. Thin Coatings on the Raw Cotton Textile Deposited by the Sol-Gel Method. Material Science Textile and Clothing Technology, 2012.

[13] Yu Q, Shen A. Anti-UV treatment for cotton fabrics by dyeing and finishing in one bath and two steps. Journal of Fiber Bioengineering and Informatics, Vol 1:65-72, 2008. 